\title{
SIZE DEPENDENCE OF SODIUM AND LITHIUM CLUSTERS IONIZATION POTENTIALS
}

\author{
Ph. DUGOURD, D. RAYANE, P. LABASTIE*, B. PINTAR, J. CHEVALEYRE, \\ M. BROYER, L. WÖSTE** and J.P. WOLF** \\ Laboratoire de Spectrométrie Ionique et Moléculaire (URA CNRS 171), Université Lyon I, \\ Bât. 205, 43 boulevard du 11 novembre 1918, F-69622 Villeurbanne cedex, France \\ *Laboratoire de Physique Quantique, Université Paul Sabatier, 118 route de Narbonne, \\ F-31062 Toulouse cedex, France \\ ${ }^{* *}$ Institut für Experimentalphysik, Freie Universität Berlin, Amimallee 14, D-1000 Berlin 33, \\ Germany
}

\begin{abstract}
The ionization potentials of $\mathrm{Li}_{n}$ and $\mathrm{Na}_{n}$ clusters are obtained by photoionization. Shell effects are observed at $n=8$ and $n=20$, as well as strong odd/even alternations. The results are compared with the spherical shell model and the ab initio calculations.
\end{abstract}

\section{1. - Introduction.}

Among metal clusters, $\mathrm{Li}_{\mathrm{n}}$ and $\mathrm{Na}_{\mathrm{n}}$ clusters are the most accessible to theoretical calculations and experimental measurements. They are then good candidates to check the variation of electronic properties from the atom to the bulk. These properties are usually interpreted in terms of the shell model [1,2] which provides a global qualitative insight of the problem. Quantitative comparison with the experiments are also very useful, especially when high level ab initio calculations are available [3]. On this point of view, the evolution of the ionization potential as a function of the size from the atomic value to the bulk work function is particularly interesting. If results have been already obtained for sodium $[4,5]$ clusters, nothing is known about lithium essentially because of the great difficulty to operate with highly reactive high temperature lithium vapor. We present in this paper the results obtained for both sodium and lithium clusters and compare them with the best theoretical calculations.

\section{2. - Experiment.}

The lithium or sodium clusters are produced in a highly cooled molecular beam, by coexpansion of 10100 mbars of lithium vapor and 1-5 bars of argon, through a $100 \mu \mathrm{m}$ nozzle. The dearth of experimental studies on lithium clusters is due to the high temperatures necessary to heat the metal and to the corrosive properties of lithium. Therefore a special oven was built. It is comprised of a cartridge made of titaniumzirconium-molybdenum which is heated by tungsten filaments and can sustain temperatures up to 1800 $\mathrm{K}$. The clusters are then ionized in a second chamber by means of a frequency doubled excimer pumped tunable dye laser. Ions are collected and mass analysed through a time of flight mass spectrometer for a given laser wavelength. By this technique, mass spectra are recorded for longer and longer wavelengths until clusters ions disappear. They are digitalized and analysed in a computer. The photoionization cross section is then deduced as a function of the photon energy, allowing the determination of the ionization threshold by linear extrapolation. 
3. - Results and discussion.

Figure 1 shows typical mass spectra recorded for different laser wavelengths. The decrease of the ionization threshold as a function of the size is clear. The lack of resolution in the mass spectra is mainly due to the existence of two isotopes ${ }^{6} \mathrm{Li}(7 \%)$ and ${ }^{7} \mathrm{Li}(93 \%)$. Beyond $\mathrm{Li}_{40}$, clusters peaks of comparable intensity may have the same mass, but a different number of atoms. This superimposition precludes the determination of the ionization potentials beyond $n \geqslant 41$. The high intensity of $\mathrm{Li}_{9,} \mathrm{Li}_{21}$ and $\mathrm{Li}_{41}$ clusters is due to their low ionization threshold. The higher intensity of odd clusters as compared to even clusters is also explained by the same reason.

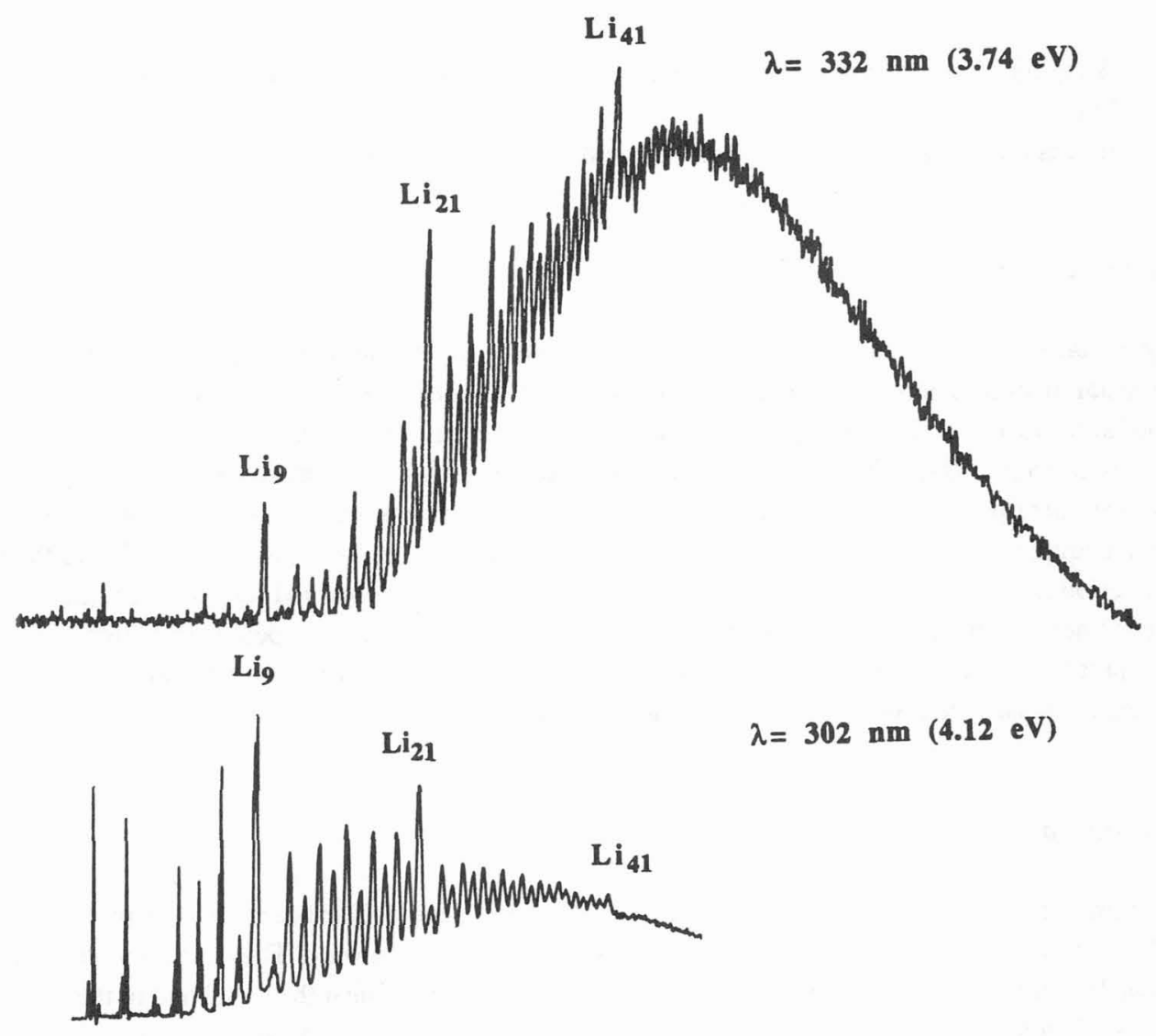

Fig. 1. - Mass spectra of $\mathrm{Li}_{\mathrm{n}}$ clusters as a function of the laser wavelength. 
The ionization potentials of $\mathrm{Li}_{\mathrm{n}}$ clusters obtained by linear extrapolation of the photoionization cross section are shown in figure 2 . Two main features must be noted :

- a clear even-odd alternation

- an abrupt decrease beyond $n=8$ and $n=21$ for clusters $\mathrm{Li}_{9}$ and $\mathrm{Li}_{21}$.

This last effect may be interpreted by the shell model $: n=8$ and $n=20$ correspond to a closed shell and the systems having 8 and 20 electrons $\left(\mathrm{Li}_{8}, \mathrm{Li}_{20}, \mathrm{Li}_{9}^{+}\right.$and $\left.\mathrm{Li}_{21}^{+}\right)$are very stable, while the systems having 9 and 21 electrons $\left(\mathrm{Li}_{9}\right.$ and $\left.\mathrm{Li}_{21}\right)$ are clearly less stable. However the spherical shell model cannot explain the odd/even alternation and strong ellipsoidal deformations are necessary [6]. However, for such small systems, the position of the nuclei remains important, and ab initio calculations [3] are necessary for quantitative comparison with the experiment. This comparison is given in Table 1 for $\mathrm{n} \leq 10$. The experimental Ionization Potential obtained by linear extrapolation is expected to be found between the adiabatic and the vertical Ionization Potential. The agreement between theory and experiment is very good and illustrates the high quality of the Koutecky group calculations [3].

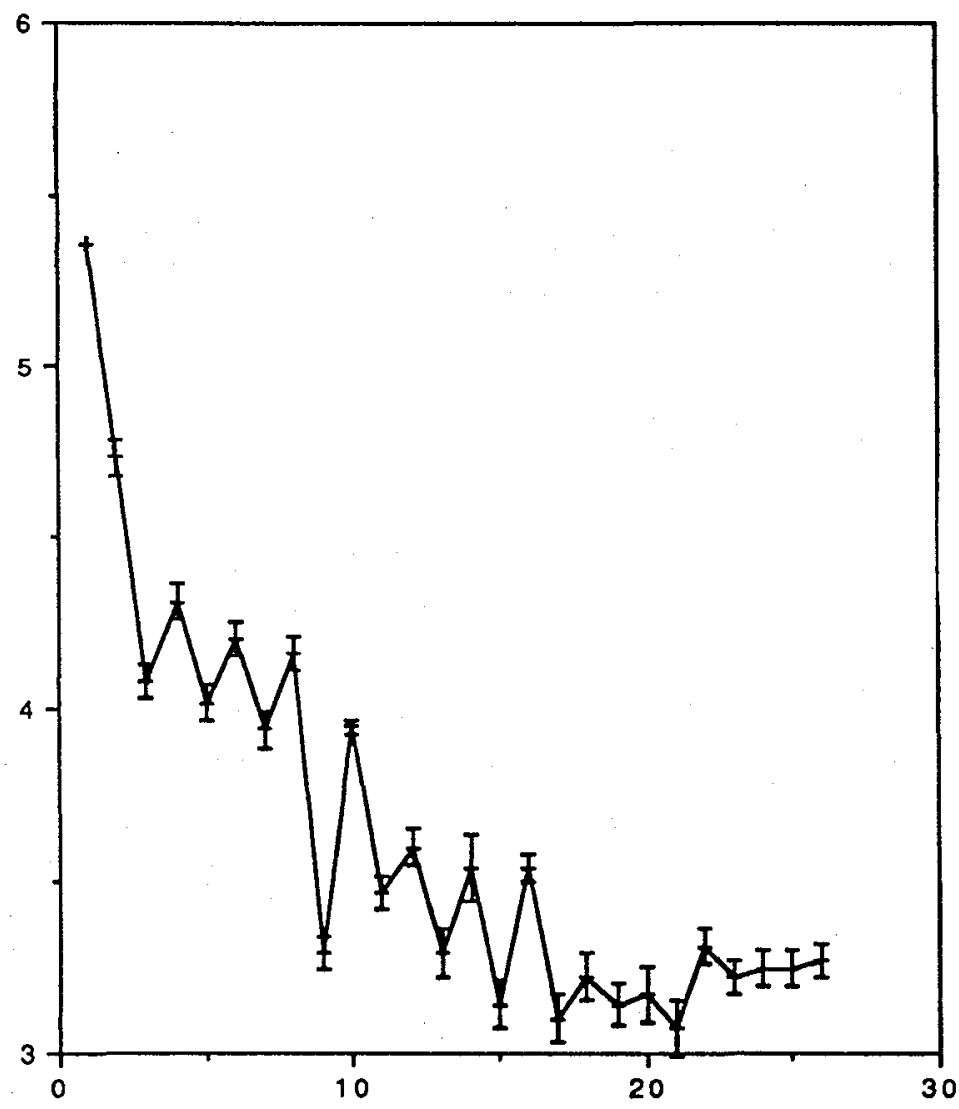

Fig. 2. - Ionization potential of $\mathrm{Li}_{\mathbf{n}}$ clusters (in $\mathrm{eV}$ ) as a function of $\mathrm{n}$. 
Table 1. - Ionization Potentials (in eV) of $\mathrm{Li}_{\mathbf{n}}$ clusters as a function of $\mathrm{n}$. IP (a) and IP (b) are respectively the adiabatic and vertical theoretical Ionization Potentials from ref. 3.

\begin{tabular}{rllll}
\hline $\mathrm{n}$ & IP exp. & incertitudes & IP (a) & IP (b) \\
\hline 1 & & & & \\
2 & 5.36 & 0.01 & & \\
3 & 4.73 & 0.05 & 5 & 4.18 \\
4 & 4.08 & 0.05 & 3.95 & 4.61 \\
5 & 4.31 & 0.05 & 4.55 & 4.48 \\
6 & 4.02 & 0.05 & 4.15 & 4.53 \\
7 & 4.20 & 0.05 & 4.32 & 3.91 \\
8 & 3.94 & 0.05 & 3.82 & 4.57 \\
9 & 4.16 & 0.05 & 4.23 & 3.70 \\
10 & 3.29 & 0.05 & 3.15 & 3.91 \\
\hline
\end{tabular}

Results have been also obtained for $\mathrm{Na}_{\mathrm{n}}$ clusters with $\mathrm{n} \leq 8$. They are given in Table 2 and compared with previous low resolution experimental results. They show similar trends.

Table 2. - Experimental Ionization Potentials (in $\mathrm{eV}$ ) of $\mathrm{Na}_{\mathrm{n}}$ clusters as a function of $\mathrm{n}$.

\begin{tabular}{llccccc}
\hline $\mathrm{n}$ & \multicolumn{1}{c}{3} & 4 & 5 & 6 & 7 & 8 \\
\hline our work & $3.95 \pm 0.05$ & $4.12 \pm 0.05$ & $3.82 \pm 0.05$ & $3.95 \pm 0.05$ & $3.82 \pm 0.05$ & $3.95 \pm 0.05$ \\
ref. 4 & $3.90 \pm 0.1$ & $4.25 \pm 0.1$ & $3.95 \pm 0.1$ & $4.2 \pm 0.1$ & $4.0 \pm 0.1$ & $4.2 \pm 0.1$
\end{tabular}

4. - Conclusion.

In conclusion, we have measured the $\mathrm{Li}_{\mathrm{n}}$ and $\mathrm{Na}_{\mathrm{n}}$ Ionization Potentials. If the results may be interpreted qualitatively by the shell model, ab initio calculations are necessary to quantitatively take into account the experimental results and the strong odd/even alternations.

[1] W.D. KNIGHT, K. CLEMENGER, W.A. de HEER, W.A. SAUNDERS, M.Y. CHOU, M.L. COHEN, Phys. Rev. Lett. 52 (1984) 2414.

[2] W.D. KNIGHT, W.A. de HEER, W.A. SAUNDERS, K. CLEMENGER, Chem. Phys. Lett. 134 (1987) 1.

[3] I. BOUSTANI, W. PERVESTORF, P. FANTUCCI, V. BONACIC-KOUTECKY, J. KOUTECKY, Phys. Rev. B 35 (1987) 9437.

[4] M.M. KAPPES, M. SCHÜR, U. ROTHLISBERGER, C. YERETZIAN, E. SCHUMACHER, Chem. Phys. Lett. 143 (1988) 251.

[5] E.C. HONEA, M.L. HORNER, J.L. PERSSON, and R.L. WHETTEN, Chem. Phys. Lett. 171 (1990) 148.

[6] K. CLEMENGER, Phys. Rev. B 32 (1985) 1953. 